\title{
Experiment Study of Ignition Characteristics in An Axial-flow-injector Burner for Stirling Engine
}

\author{
Liu Kun ${ }^{1, *}$, Lu $\operatorname{Tian}^{1}$, Lan Jian ${ }^{1}$, Huang Xiaoyu ${ }^{1}$, and Yin Guofeng ${ }^{1}$ \\ ${ }^{1}$ Shanghai Marine Diesel Engine Research Institute Editorial Department, Shanghai, China
}

\begin{abstract}
To investigate the ignition characteristics of an axial-flow injection burner for a Stirling engine, a combustion chamber was designed. Diesel was used as fuel and oxygen as oxidant. The experiments of ignition characteristics were carried out with an electric plug igniter. The ignition characteristics under different combustion chamber pressure, pre-oxygen supply time, oxygen supply flow and ignition position were studied. The experimental results show that, with the increase of the pressure, the ignition time of the burner increases gradually, and the ignition success rate decreases gradually. The oxygen flow rate is related to ignition time in a certain range, while the pre-oxygen supply time has little effect. With the ignition position moving downward, the ignition time decreases gradually.
\end{abstract}

\section{Introduction}

Combustion Gas Recirculation（CGR） technology is one of the common technologies in Stirling engine burner design. The technology is to use the ejecting and mixing effect of gas flow.Through the high-speed airflow from the nozzle, a negative pressure area is formed in the ejector tube. Part of the high-temperature exhaust gas after heat exchange is injected into the ejector tube to mix with oxygen to form oxidant with appropriate concentration, and then mixed with oil mist to re-enter the main combustion zone for combustion reaction.Part of the gas generated by combustion is discharged from the combustion chamber, and the other part is ejected to participate in combustion again, so as to establish a stable process of gas cycle $[1 \sim 4]$. By injecting the combustion exhaust gas into the combustion process again, the flame temperature can be reduced and NOx generation can be inhibited. In the meanwhile, the high-speed gas flow from the ejector can promote the forced circulation of the gas flow in the combustion chamber, which can strengthen the convective heat transfer and improve the uniformity of the temperature distribution in the combustion chamber $[5,6]$.

For the ignition characteristics of Stirling engine ejector burner, the relevant research content is less reported. In this paper, a combustion test-bed is set up for the axial-flow injection burner used in a Stirling engine. Diesel oil and oxygen are used as fuel and oxidant, and electric plug ignition is adopted. The ignition characteristics of different combustor pressure, oxygen flow rate, pre oxygen time and ignition position were studied. The main factors affecting the ignition characteristics of the burner are analyzed, which has

*Corresponding author: liukun_012@163.com 
a certain guiding significance for the study of its injection and combustion characteristics and the design of the burner.

\section{Experimental system and method}

\subsection{Brief introduction of experimental system}

In this experiment, the ignition characteristics of an axial-flow injection burner were studied. The structure of the burner is shown in Fig. 1, which is mainly composed of base, fuel injection nozzle, cyclone, oxygen distribution chamber, oxygen nozzle, injection pipe, igniter and flame temperature thermocouple. Fig. 2 is the physical diagram of the burner.

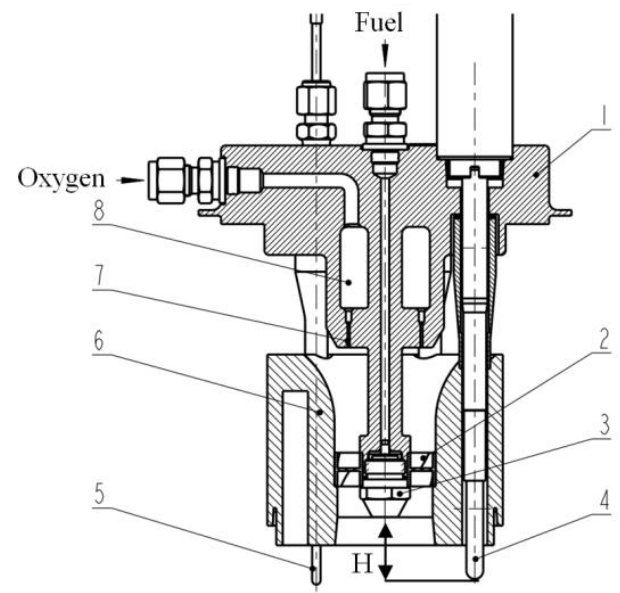

1- Base, 2- Cyclone, 3- Fuel injection nozzle, 4- Igniter, 5- Flame temperature thermocouple, 6- Injection pipe, 7- Oxygen nozzle, 8- Oxygen distribution chamber

Fig. 1. Structure diagram of burner
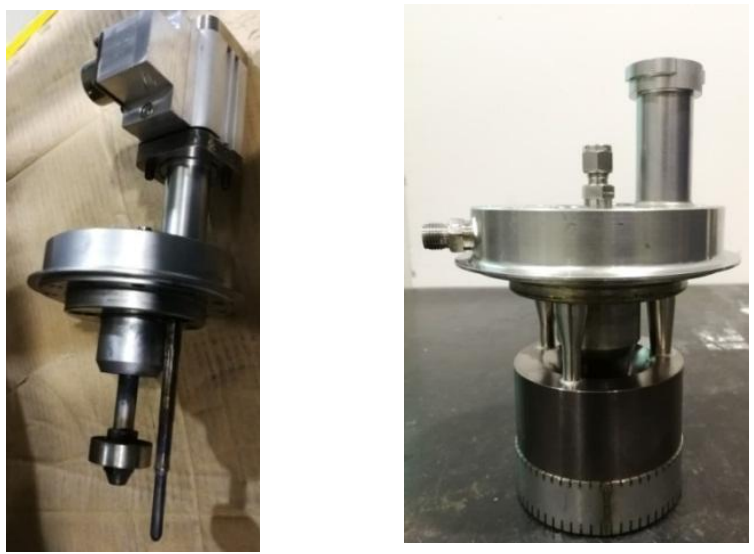

Fig. 2. Physical drawing of burner

The nozzle is a pressure swirl nozzle with a rated flow rate of $3.0 \mathrm{~kg} / \mathrm{h}$ and a designed cone angle of $90^{\circ}$. The ejector tube is designed with equal cross-section circumferential direction for multi-jet. A section of cylindrical tube with equal cross-section is used as the 
mixing section of the ejector tube. With the mixing of active and passive gas flow, the static pressure of the gas flow along the axis of the nozzle increases continuously, so that a uniform mixed gas flow can be obtained at the outlet of the ejector tube. The mass ratio of the injected air flow is 4.8. The cyclone (as shown in Fig. 3) is composed of 8 swirlers with a swirl number of 0.35 . The structure of the oxygen nozzle is a direct injection hole with a diameter of $0.8 \mathrm{~mm}$. Four oxygen nozzles are evenly distributed at the bottom of the oxygen distribution chamber. The glow plug is used as the heating body of the igniter. After being electrified, it forms an ignition heat source with a surface temperature of about $850{ }^{\circ} \mathrm{C}$.The distance from the head of igniter to the lower end of nozzle is defined as ignition position, which is indicated by letter $\mathrm{H}$.

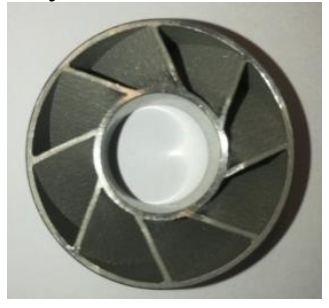

Fig. 3. Physical drawing of cyclone

Around this type of burner, a combustion test-bed is designed and built, as shown in Figure 4.The test-bed consists of a simulated combustion chamber composed of burner, pressure shell and cooling water bench, as well as oil and oxygen control solenoid valve group and monitoring system. The simulated combustion chamber is a cylindrical space with a diameter of $170 \mathrm{~mm}$ and a height of $250 \mathrm{~mm}$. The cooling water pipe is set inside to provide the function of rapid cooling after the experiment and the safety protection of the experimental system.

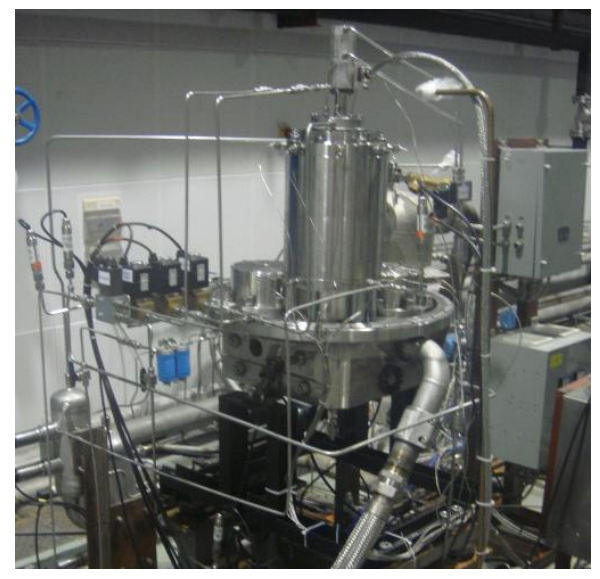

Fig. 4. Physical drawing of combustion test-bed

In the experiment, fuel and oxygen at room temperature were used for combustion. The fuel oil is heavy diesel, and its main physical parameters are shown in Table 1. 
Table 1. Main physical parameters of fuel

\begin{tabular}{c|c|c|c|c}
\hline $\begin{array}{c}\text { Temperature } \\
\left({ }^{\circ} \mathbf{C}\right)\end{array}$ & $\begin{array}{c}\text { Kinematic } \\
\text { viscosity } \\
\left(\mathbf{m}^{2} / \mathbf{s}\right)\end{array}$ & $\begin{array}{c}\text { Density } \\
\left(\mathbf{k g} / \mathbf{m}^{\mathbf{3}}\right)\end{array}$ & $\begin{array}{c}\text { Specific heat } \\
(\mathbf{k J} / \mathbf{k g} \cdot \mathbf{K})\end{array}$ & $\begin{array}{c}\text { Thermal } \\
\text { conductivity } \\
(\mathbf{W} / \mathbf{m} \cdot \mathbf{K})\end{array}$ \\
\hline 10 & $1.12 \mathrm{e}-5$ & 819.9 & 2070 & 0.14 \\
20 & $7.89 \mathrm{e}-6$ & - & - & - \\
30 & $5.84 \mathrm{e}-6$ & 807.5 & - & - \\
40 & $4.54 \mathrm{e}-6$ & - & - & - \\
50 & $3.68 \mathrm{e}-6$ & 794.3 & - & - \\
\hline
\end{tabular}

\subsection{Experimental methods}

At the beginning of the experiment, the simulated combustion chamber was purged with nitrogen, the gas composition was initialized, and the back pressure of the combustion chamber was adjusted to the set value.After purging, the igniter was powered on and preheated for 30 seconds to make the glow plug reach a stable high temperature state. Then, the oxygen supply solenoid valve was opened, and the oxygen entered the oxygen distribution chamber of the burner from the inlet, and was charged into the simulated combustion chamber through four oxygen nozzles. When the oxygen concentration in the combustion chamber reached the preset concentration, the fuel supply solenoid valve was opened, and the fuel was injected with the rated fuel volume of the nozzle $(3.0 \mathrm{~kg} / \mathrm{h})$. At the same time, the oxygen flow was adjusted to the set value, and the indication of the flame temperature thermocouple was observed and recorded.

In this experiment, the ignition delay time was defined as the time from the opening of the fuel supply solenoid valve to the time when the flame temperature thermocouple detects the obvious temperature rise in the simulated combustion chamber. In addition, in order to ensure the safety of the experiment, if no ignition was observed within 30 seconds from the beginning of fuel supply, the ignition failure was judged and the experiment was terminated.

\section{Results and analysis}

\subsection{Influence of combustion chamber pressure on ignition characteristics}

Figure 5 shows the relationship between ignition delay time, ignition success rate and combustion chamber back pressure. It can be seen from the experimental results that the ignition success rate of full probability can be maintained and the ignition delay time is short under the conditions of $1 \mathrm{MPa}$ and $2 \mathrm{MPa}$ with low combustion chamber pressure. However, with the increase of pressure, the ignition success rate gradually decreases, and the ignition delay time increases significantly. The reason is that with the increase of pressure, the gas density in the combustion chamber increases gradually, and the velocity of the atomized fuel droplet decreases rapidly due to the effect of the ambient gas resistance. As a result, the atomization cone angle of the nozzle decreases and the mixing effect of oil mist and oxygen becomes worse. At the same time, the vaporization temperature of droplets also increases with the increase of pressure, resulting in the increase of droplet heating time and the decrease of vaporization rate, which leads to the increase of ignition delay time and the decrease of ignition success rate. 


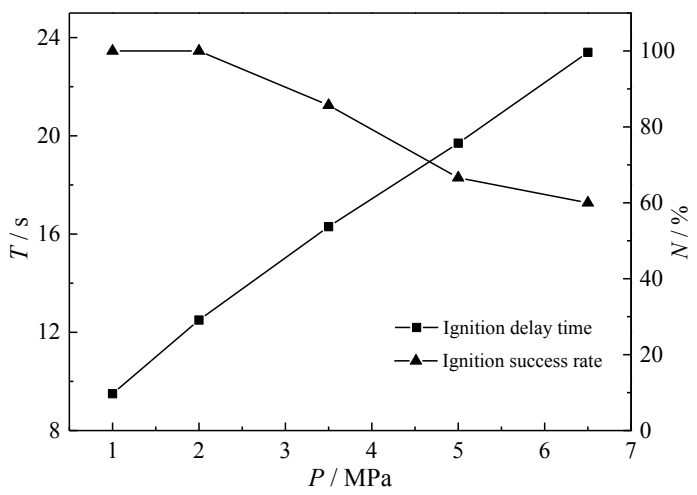

Fig. 5. Influence of combustion chamber pressure on ignition characteristics $\left(m_{\mathrm{oil}}=3 \mathrm{~kg} / \mathrm{h}, \quad m_{\mathrm{O} 2}=24 \mathrm{~kg} / \mathrm{h}\right)$

\subsection{Influence of oxygen flow rate on ignition characteristics}

Figure 6 shows the relationship between ignition delay time and oxygen flow rate under different back pressure. It can be found that the ignition delay time decreases with the increase of oxygen flow rate. However, when the oxygen flow rate continues to increase, it has little effect on the ignition delay time. For example, when the oxygen flow rate is increased from $16 \mathrm{~kg} / \mathrm{h}$ to $20 \mathrm{~kg} / \mathrm{h}$ at $1 \mathrm{MPa}$, the ignition delay time can be shortened by nearly $4 \mathrm{~s}$. When the oxygen flow rate is further increased, the ignition delay time does not decrease significantly. Similarly, the variation trend of ignition delay time is similar when the oxygen flow rate is $24 \mathrm{~kg} / \mathrm{h}$ at $2 \mathrm{MPa}$ and $3.5 \mathrm{MPa}$.

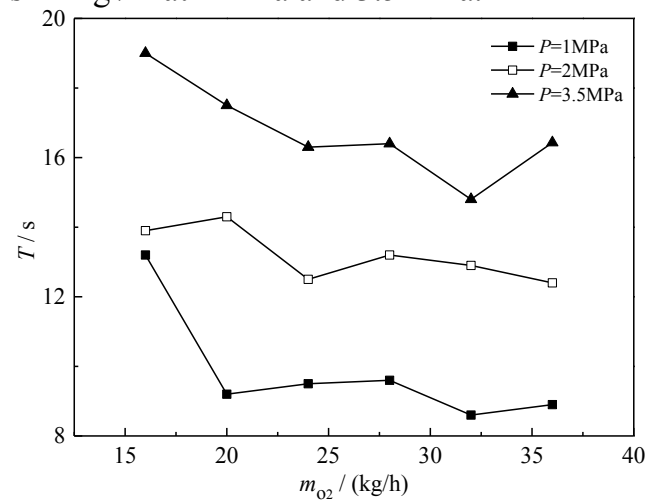

Fig. 6. Relationship between ignition delay time and oxygen flow rate

$$
\left(m_{\mathrm{oil}}=3 \mathrm{~kg} / \mathrm{h}\right)
$$

This phenomenon shows that the ignition process of this type of burner can be accelerated by increasing the oxygen flow rate to a certain extent. This is because, with the increase of oxygen flow, the amount of ejected flue gas also increases, and the flow velocity at the exit of the ejector increases, which is conducive to the diffusion of oil mist and improves the probability of oil mist being ignited in contact with the igniter. But at the same time, with the increase of oxygen flow into the combustion chamber and gas flow rate in the combustion chamber, the convective heat transfer effect between igniter and gas will be enhanced, resulting in the decrease of surface temperature of igniter. Even if the initial fire source is formed after ignition, too fast gas flow may lead to flame stripping or blowing out, which is not conducive to the development and propagation of flame. 


\subsection{Influence of pre oxygen concentration on ignition characteristics}

Figure 7 shows the effect of pre oxygen concentration on ignition characteristics under different back pressure. It can be seen from the figure that the change trend of ignition delay time is not obvious when the pre supply oxygen concentration is gradually increased from $21 \%$ to more than $40 \%$ under the pressure condition of each combustion chamber. Combined with the influence of oxygen flow rate on ignition characteristics in Section 3.2, it can be reflected that the ignition speed of the burner is not sensitive to the change of ambient gas concentration, but more significant to the change of gas flow rate.

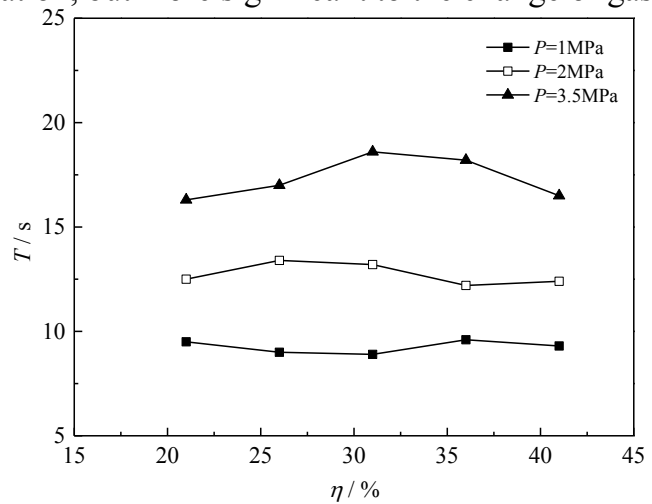

Fig. 7. Relationship between ignition delay time and pre oxygen concentration $\left(m_{\mathrm{oil}}=3 \mathrm{~kg} / \mathrm{h}, \quad m_{\mathrm{O} 2}=24 \mathrm{~kg} / \mathrm{h}\right)$

\subsection{Influence of ignition position on ignition characteristics}

Figure 8 shows the relationship between ignition delay time and ignition position under different combustion chamber pressures. It is found that the ignition delay time decreases with the increase of ignition position. In the low pressure condition, the ignition delay time changes slightly, while in the high $3.5 \mathrm{Mpa}$ condition, it can be observed that the ignition delay time is significantly shortened by nearly $30 \%$. This is due to the downward shift of ignition position, which can make the high-temperature heat source closer to the fuel atomization area. Driven by the jet flow, the liquid mist will spread to the igniter more quickly and form a fire source. Compared with the low pressure condition, the influence of ignition position change on ignition delay time is more obvious at higher pressure condition. This shows that the diffusion process of oil mist oxygen mixture to high temperature heat source plays an important role in the ignition delay time of this type of axial-flow injection burner under high pressure conditions 


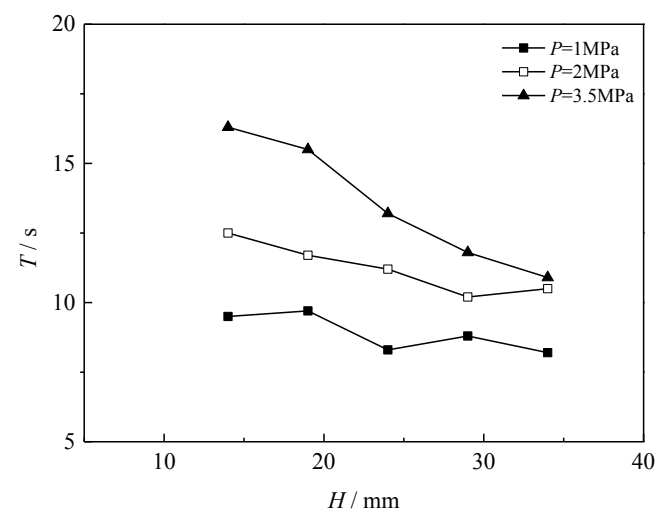

Fig. 8. Relationship between ignition delay time and ignition position $\left(m_{\mathrm{oil}}=3 \mathrm{~kg} / \mathrm{h}, \quad m_{\mathrm{O} 2}=24 \mathrm{~kg} / \mathrm{h}\right)$

\section{Conclusion}

In this paper, a combustion test-bed is set up for the axial-flow injection burner used in a Stirling engine. The ignition characteristics are studied experimentally. The main conclusions are as follows

(1) With the increase of combustion chamber pressure, the ignition success rate of the burner decreases gradually, and the ignition delay time increases obviously;

(2) With the increase of oxygen flow rate, the ignition delay time shows a decreasing trend, which is relatively obvious in the range of low oxygen flow rate, and has little effect on the ignition delay time when the oxygen flow rate continues to increase;

(3) With the increase of oxygen concentration, the ignition delay time is not obvious;

(4) With the increase of ignition position, the ignition delay time of the combustor at different pressures generally decreases, and it can be observed that the ignition delay time is significantly shortened at higher back pressure.

\section{References}

[1] Jin Donghan. Stirling engine technology (Harbin Engineering University Press, 2009)

[2] Martini W R. Stirling Engine Design Manual (2nd. NASA CR-168088, 1983)

[3] Gu Genxiang, Peng Xiaofang, Pan Weiming, Lu Tian. Development and application of Stirling technology (Harbin Engineering University Press, 2020)

[4] Lewandowski E J, Regan T F. Overview of the GRC Stirling Convertor System Dynamic Model. NASA/CR- 2004- 213366, (2004)

[5] Walker G. StirlingEngines (Oxford University Press, 1980)

[6] Zhang Z, Ibrahim M B. Development of CFD Model for Stirling Engine and its Components. AIAA 2nd IECEC, Providence, RI, AIAA-2004-5674, (2004) 